\title{
Hypervolemia increases release of atrial natriuretic peptide and shedding of the endothelial glycocalyx
}

\author{
Daniel Chappell ${ }^{1 \dagger}$, Dirk Bruegger ${ }^{1 * \dagger}$, Julia Potzel ${ }^{1}$, Matthias Jacob ${ }^{1}$, Florian Brettner ${ }^{1}$, Michael Vogeser ${ }^{2}$, \\ Peter Conzen", Bernhard F Becker ${ }^{3}$ and Markus Rehm
}

\begin{abstract}
Introduction: Acute normovolemic hemodilution (ANH) and volume loading (VL) are standard blood-sparing procedures. However, VL is associated with hypervolemia, which may cause tissue edema, cardiopulmonary complications and a prolonged hospital stay. The body reacts to hypervolemia with release of atrial natriuretic peptide (ANP) from the heart. ANP has been shown to deteriorate the endothelial glycocalyx, a vital part of the vascular permeability barrier. The aim of the present study was to evaluate and compare ANP release and damage to the glycocalyx during $\mathrm{ANH}$ and $\mathrm{VL}$.

Methods: ANH or VL with 6\% hydroxyethyl starch 130/0.4 was administered prior to elective surgery in patients of good cardiopulmonary health ( $n=9$ in each group). We measured concentrations of ANP in plasma and of three main constituent parts of the glycocalyx (hyaluronan, heparan sulfate and syndecan 1) in serum before and after ANH or VL. Heparan sulfate and syndecan 1 levels in urine were also determined.

Results: In contrast to ANH, VL $(20 \mathrm{ml} / \mathrm{kg}$ ) induced a significant release of ANP (approximately $+100 \%, P<0.05)$ and increased the serum concentration of two glycocalyx constituents, hyaluronan and syndecan 1 (both by about $80 \%$, $P<0.05$ ). Elevation of syndecan 1 was also detected in the urine of patients undergoing $V L$, but no increase was found in patients undergoing ANH. Heparan sulfate levels were not influenced by either procedure.
\end{abstract}

Conclusion: These data suggest that hypervolemia increases the release of ANP and causes enhanced shedding of the endothelial glycocalyx. This perturbation must be expected to impair the vascular barrier, implying that VL may not be as safe as generally assumed and that it should be critically evaluated.

\section{Introduction}

On the surface of healthy vascular endothelium resides a structure, the endothelial glycocalyx, that consists of extracellular domains of receptor, adhesion and channel proteins and, foremost, of molecules such as transmembrane syndecan 1 (bearing covalently bound, highly negatively charged glycosaminoglycans, such as heparan and chondroitin sulfates) and the receptor-bound, longchained hyaluronic acid molecule [1,2]. Together with bound plasma proteins and glycosaminoglycans, the glycocalyx forms the endothelial surface layer with a functional thickness of more than $1 \mu \mathrm{m}[3,4]$. Disruption of the glycocalyx has been shown to increase capillary

\footnotetext{
* Correspondence: dirk.bruegger@med.uni-muenchen.de

${ }^{\dagger}$ Equal contributors

'Department of Anesthesiology, University Hospital of Munich, Marchioninistrasse 15, 81377 Munich, Germany

Full list of author information is available at the end of the article
}

permeability and firm attachment of leukocytes and blood platelets, leading to tissue edema, suggesting that the glycocalyx acts as a competent permeability barrier and antiadhesive interface with blood [5]. In patients in septic shock, glycocalyx shedding has been found to be associated with increased mortality and to be an independent predictor of mortality in trauma patients [6-8].

Traditional perioperative fluid therapy is often performed in a liberal manner, leading to fluid overload and tissue edema. In clinical studies, hypervolemia has been shown to have detrimental influences on several aspects of patient outcome, including cardiopulmonary complications, anastomotic insufficiency, length of hospital stay, duration of mechanical ventilation and mortality [9-11]. One possible underlying trigger may be the release of atrial natriuretic peptide (ANP) from the cardiac atria invoked by mechanical wall stress [12]. ANP is known to induce rapid shifts of intravascular fluid into the interstitial 
space and has been shown to cause deterioration of the endothelial glycocalyx. In an isolated heart model, artificially infused ANP induced an increase in vascular permeability, a histologically detectable degradation of the glycocalyx and significant tissue edema [13]. Furthermore, an increase in plasma ANP has been found to precede shedding of the glycocalyx in patients undergoing coronary bypass surgery [14].

ANP is released during hypervolemia, which could explain the context sensitivity of volume effects of isooncotic colloidal infusions (for example, 6\% hydroxyethyl starch or $5 \%$ human albumin) $[15,16]$. The "volume effect" is that part of an infused fluid bolus that remains within the vasculature for a longer period. Direct blood volume measurements have revealed that the presumed volume effect of about $100 \%$ for such colloids is realized only in normovolemic patients-that is, during acute normovolemic hemodilution $(\mathrm{ANH})$, a procedure in which blood is withdrawn and simultaneously replaced by equal amounts of colloidal fluid [16]. During volume loading (VL) (that is, the hypervolemic infusion of colloids into a primarily normovolemic circulation without simultaneous blood withdrawal), about $60 \%$ of the infused amount was observed to directly load the interstitial space within 30 minutes, leaving a volume effect of merely $40 \%$ [15]. Also, $60 \%$ of the infused fluid was found to leave the intravascular space, and $60 \%$ of the administered macromolecules (hydroxyethyl starch (HES) and albumin) were extravasated.

The aim of the present study was to investigate comparatively whether the established blood-sparing procedures VL (hypervolemia) and ANH (normovolemia) are associated with increased ANP levels and shedding of the endothelial glycocalyx.

\section{Material and methods}

The study was approved by the independent ethics committee of our institution (Medical Faculty of the Ludwig-Maximilians-University Munich, Germany; trial registration 128-04), and all patients included gave us their written informed consent to participate. Inclusion criteria were patient consent, good cardiopulmonary health, expected blood loss of more than $500 \mathrm{ml}$, and preoperative indication of the necessity to insert arterial and central venous catheters. The study was performed before the results of the $6 \mathrm{~S}$ and CHEST trials were published (Scandinavian Starch for Severe Sepsis/Septic Shock trial and Crystalloid versus Hydroxyethyl Starch trial, respectively) $[17,18]$.

\section{Anesthesiological procedure}

The mandatory fasting period after consumption of solid food, milk and milk-containing fluids was 6 hours, and clear fluids were allowed up to 2 hours before induction of anesthesia. After each patient arrived in the operating theatre, monitoring with electrocardiography and pulse oximetry was implemented. General anesthesia was induced with $0.5 \mu \mathrm{g} / \mathrm{kg}$ sufentanil, $2 \mathrm{mg} / \mathrm{kg}$ propofol and $0.1 \mathrm{mg} / \mathrm{kg}$ cisatracurium, and, after tracheal intubation, anesthesia was maintained with $1.6 \%$ to $2.0 \%$ sevoflurane. Radial artery and central venous catheters were inserted. Mechanical ventilation was performed to maintain partial pressure of arterial oxygen at 100 to $150 \mathrm{mmHg}$ and partial pressure of carbon dioxide at $40 \pm 5 \mathrm{mmHg}$. No intravenous infusions were applied, except for negligible amounts required to inject the intravenous drugs. After a steady state was achieved, the patients were assigned to receive either VL or ANH.

\section{Acute normovolemic hemodilution}

Blood was removed at a rate of about $60 \mathrm{ml} / \mathrm{min}$ via the arterial line and simultaneously replaced with iso-oncotic HES colloid solution (6\% HES 130/0.4 (Volulyte); Fresenius Kabi, Bad Homburg, Germany) at almost the same rate through the central venous line. At first, a quantity of approximately $500 \mathrm{ml} / \mathrm{m}^{2}$ of blood was removed. The hemodilution bags were weighed on a precision scale so that the volume of withdrawn blood could be evaluated immediately. For fine-tuning, frequent determinations of hematocrit were carried out to reach a target hematocrit level of $24 \pm 2 \%$. The hemodilution procedure took about 30 minutes.

\section{Volume loading}

VL was initiated by infusing $20 \mathrm{ml} / \mathrm{kg}$ of an iso-oncotic HES colloid solution (6\% HES 130/0.4, Volulyte) within 15 minutes at a rate of approximately $90 \mathrm{ml} / \mathrm{min}$.

\section{Blood sampling}

In all patients, blood and urine samples were taken directly after induction of anesthesia (pre) to determine basal values. Both $\mathrm{VL}$ and $\mathrm{ANH}$ procedures were initiated immediately thereafter and lasted for 30 minutes, followed by the second blood and urine sampling (post). The time window for the present study was chosen because we knew from previous direct double-tracer blood volume measurements that, after VL with $5 \%$ human albumin or $6 \%$ HES administration, the total volume of the endothelial surface layer (glycocalyx and bound plasma proteins) would be significantly reduced 30 minutes after the procedure [15]. The patients were kept strictly in supine position during the whole investigation period. All measurements were performed before surgical incisions were made.

\section{Determination of glycocalyx constituents}

Immediately after withdrawal into serum vials, blood samples were centrifuged at 2,000 $g$ for 10 minutes. The serum fraction was frozen and stored at $-80^{\circ} \mathrm{C}$ until 
assayed. Urine samples were also frozen at $-80^{\circ} \mathrm{C}$ until assayed.

\section{Syndecan 1 concentration}

Syndecan 1 concentrations in serum and urine were determined directly as previously reported by using an enzymelinked immunosorbent assay kit (Diaclone Research, Besancon, France) $[14,19,20]$. In this kit, a solid-phase monoclonal B-B4 antibody against an extracellular domain of syndecan 1 is employed.

\section{Heparan sulfate concentration}

Serum and urinary heparan sulfate concentrations were quantified using a special enzyme-linked immunosorbent assay kit (Seikagaku, Tokyo, Japan) as previously reported $[14,19,21-23]$. Serum was pretreated with protease from Streptomyces griseus (Actinase E; Sigma-Aldrich, St Louis, MO, USA). This kit employs two monoclonal antibodies specific for heparan sulfate-related epitopes.

\section{Hyaluronan concentration}

Hyaluronan concentrations were measured in serum using an enzyme-linked immunosorbent assay kit (Echelon Biosciences, Salt Lake City, UT, USA) designed to detect human hyaluronic acid, as previously described [14,23]. Hyaluronan concentrations were not measured in urine, because renal excretion plays a negligible part in clearance. The major part of the elimination of hyaluronan (about 90\%) from the systemic circulation occurs in the liver via receptor-mediated endocytosis in the sinusoidal liver endothelial cells $[24,25]$.

\section{Atrial natriuretic peptide concentration}

Blood was sampled into ethylenediaminetetraacetic acid in vials and centrifuged immediately $(2,000 \mathrm{~g}, 10$ minutes). The plasma was directly frozen and stored at $-80^{\circ} \mathrm{C}$ until assayed. Plasma levels of ANP were measured with a sandwich enzyme-linked immunosorbent assay kit (Uscn Life Science, Wuhan, China) with an antibody specific to human ANP as performed previously [14]. The kit did not require a preliminary step for extraction or purification of plasma samples.

\section{Statistical analysis}

A preliminary sample size calculation was based on a previous study in which researchers investigated ANP concentrations after VL with $500 \mathrm{ml}$ of $6 \%$ HES and $1,000 \mathrm{ml}$ of Ringer's lactate solution in patients before caesarean section [26]. The difference between mean ANP before and after VL was $17.9 \mathrm{pg} / \mathrm{ml}$. Using this difference and the corresponding standard deviations, we calculated a sample size with a two-sided confidence interval of 0.95 and a desired power of 0.80 , which yielded a result that we needed nine patients in each group. Data are given as mean \pm SEM. All data were compared by performing Student's $t$-test, with $P<0.05$ considered statistically significant (SigmaStat; Systat Software, Richmond, VA, USA).

\section{Results}

Demographic data and procedural characteristics

All patients were attested to be in good cardiopulmonary health and were scheduled for elective general surgery with an expected blood loss greater than $500 \mathrm{ml}$. As the measuring time points were all before skin incision, the individual diagnosis and operation had no influence on the study. The pertinent patient characteristics and initial albumin concentrations are listed in Table 1. Patients in the VL group received $1,326 \pm 50 \mathrm{ml}$ of $6 \%$ HES solution after induction of anesthesia. In the ANH group, $1,267 \pm 62 \mathrm{ml}$ of blood were drawn and simultaneously replaced with similar amounts of 6\% HES 130/0.4. Notably, urine production was not increased in the VL group compared to the ANH group during the first 30minute period of the intervention.

\section{Atrial natriuretic peptide}

All data are normalized to grams per deciliter of plasma albumin to account for varying degrees of hemodilution in individual patients. Basal ANP concentrations in plasma showed no difference between the VL and ANH groups $(13.6 \pm 6.2 \mathrm{ng} / \mathrm{g}$ vs. $13.4 \pm 3.5 \mathrm{ng} / \mathrm{g}$ albumin). Thirty minutes after the procedures, ANP concentrations had increased in the VL group to $25.1 \pm 11.4 \mathrm{ng} / \mathrm{g}$ albumin, whereas the ANP concentration in the ANH group remained almost unchanged at $14.8 \pm 5.6 \mathrm{ng} / \mathrm{g}$ albumin $(P<0.05)$ (Figure 1).

\section{Shedding of components of the endothelial glycocalyx}

To account for hemodilution, individual heparan sulfate, hyaluronan and syndecan 1 concentrations were normalized to the individual albumin concentrations. Respective

Table 1 Patient characteristics ${ }^{\mathrm{a}}$

\begin{tabular}{lll}
\hline & VL & ANH \\
\hline Age $(\mathrm{yr})$ & $57 \pm 4$ & $55 \pm 2$ \\
Height $(\mathrm{cm})$ & $170 \pm 2$ & $166 \pm 2$ \\
Weight $(\mathrm{kg})$ & $67 \pm 3$ & $64 \pm 4$ \\
BSA $\left(\mathrm{m}^{2}\right)$ & $1.8 \pm 0.1$ & $1.7 \pm 0.1$ \\
Blood removed $(\mathrm{ml})$ & & $1,267 \pm 62$ \\
Colloid infused $(\mathrm{ml})$ & $1,326 \pm 50$ & $1,298 \pm 71$ \\
Urine production $(\mathrm{ml})$ & $213 \pm 66$ & $228 \pm 29$ \\
Baseline serum albumin (g/dl) & $4.1 \pm 0.1$ & $4.1 \pm 0.1$ \\
\hline
\end{tabular}

${ }^{a}$ Values are given as mean \pm SEM. There were no significant differences between the VL and ANH groups with respect to applicable parameters. Urine production was determined 30 minutes after fluid infusion (VL) or 30 minutes after blood draw $(\mathrm{ANH})$, respectively. $\mathrm{ANH}$, Acute normovolemic hemodilution; BSA, Body surface area; VL, Volume loading. 


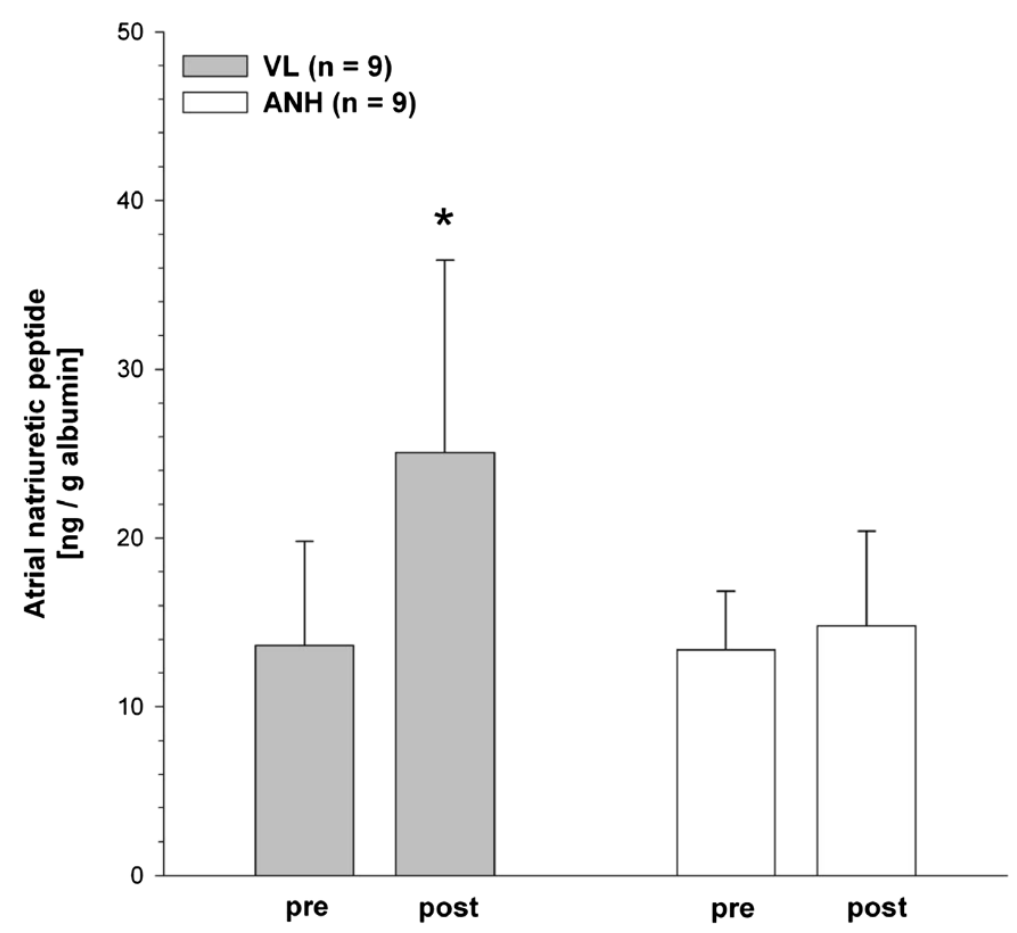

Figure 1 Atrial natriuretic peptide concentrations. Atrial natriuretic peptide concentrations before (pre) and after (post) volume loading $(\mathrm{VL}, n=9)$ or acute normovolemic hemodilution $(\mathrm{ANH}, n=9)$ with $6 \%$ hydroxyethyl starch 130/0.4. To account for hemodilution, individual atrial natriuretic peptide concentrations were normalized to the individual albumin concentrations. Data are given as mean \pm SEM. ${ }^{*} P<0.05$ (significantly different from pre).

baseline values of heparan sulfate, hyaluronan and syndecan 1 concentrations did not differ between the groups (heparan sulfate: $2.8 \pm 0.7 \mu \mathrm{g} / \mathrm{g}$ albumin vs. $2.6 \pm 0.6 \mu \mathrm{g} / \mathrm{g}$ albumin; hyaluronan: $32.6 \pm 5.5 \mu \mathrm{g} / \mathrm{g}$ albumin vs. $32.7 \pm$ $3.7 \mu \mathrm{g} / \mathrm{g}$ albumin; syndecan $1: 24.8 \pm 8.1$ vs. $30.1 \pm 8.4 \mu \mathrm{g} / \mathrm{g}$ albumin) (Figure 2). Figure 2 illustrates the changes in the concentrations of the three glycocalyx constituents in both groups. Serum heparan sulfate concentrations remained almost unchanged after both VL and ANH (Figure 2a). Interestingly, the serum hyaluronan concentration increased significantly to $56.4 \pm 12.2 \mu \mathrm{g} / \mathrm{g}$ albumin in the VL group 30 minutes after the procedure, whereas the level remained unchanged in the ANH group (Figure 2b). Also, a significant increase in serum syndecan 1 concentration to $45.4 \pm 14.9 \mu \mathrm{g} / \mathrm{g}$ albumin was found in the VL group 30 minutes after VL. Again, no change in serum syndecan 1 was seen 30 minutes after ANH (Figure 2c).

\section{Renal excretion of components of the endothelial glycocalyx}

Figure 3 shows the changes in urinary concentrations of two glycocalyx components known to pass through the glomerular barrier. Urinary heparan sulfate concentrations remained unchanged both after VL and after ANH (Figure 3a). In contrast, urinary syndecan 1 concentrations increased significantly in the VL group 30 minutes after VL $(P<0.05)$. No such increase was found in the ANH group (Figure $3 b)$.

\section{Discussion}

The results of the present study reveal that hypervolemia induced by VL is associated with increased plasma concentrations of ANP and raised serum levels of two main constituents of the endothelial glycocalyx. ANH had no comparable effects.

ANH and VL are well-established, frequently used blood-sparing procedures. The main goal of $\mathrm{ANH}$ is to withdraw whole blood, which is stored outside the body, and replace this volume with iso-oncotic colloids, thereby diluting the remaining blood whilst retaining a constant normovolemic blood volume [27]. In this situation, isooncotic colloids have a volume effect of nearly $100 \%$, meaning that the entire infused volume remains in the circulation [16]. In the event of subsequent bleeding, there is a loss of diluted, hemoglobin-reduced blood, which can be replaced with the previously withdrawn hemoglobin-rich blood when the individual transfusion cutoff value is reached. VL, in contrast, dilutes the blood by expanding the blood volume [27]. In previous studies, direct blood volume measurements have revealed that, during the VL procedure, only $40 \%$ of the infused colloids remain within the vasculature [15]. The other $60 \%$ are shifted to the 
Figure 2 Serum concentrations of glycocalyx components.

Serum concentrations of heparan sulfate (a), hyaluronan (b) and syndecan 1 (c) before (pre) and after (post) volume loading (VL, $n=9)$ or acute normovolemic hemodilution $(\mathrm{ANH}, n=9)$ with $6 \%$ hydroxyethyl starch 130/0.4. To account for hemodilution, individual heparan sulfate, hyaluronan and syndecan 1 concentrations were normalized to the individual albumin concentrations. Data are given as mean \pm SEM. ${ }^{*} P<0.05$ (significantly different from pre).

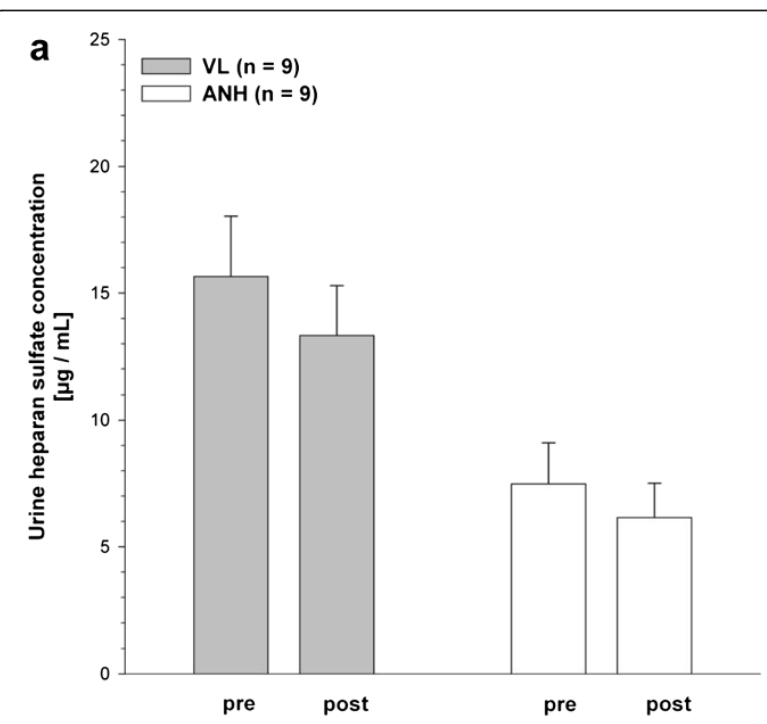

b

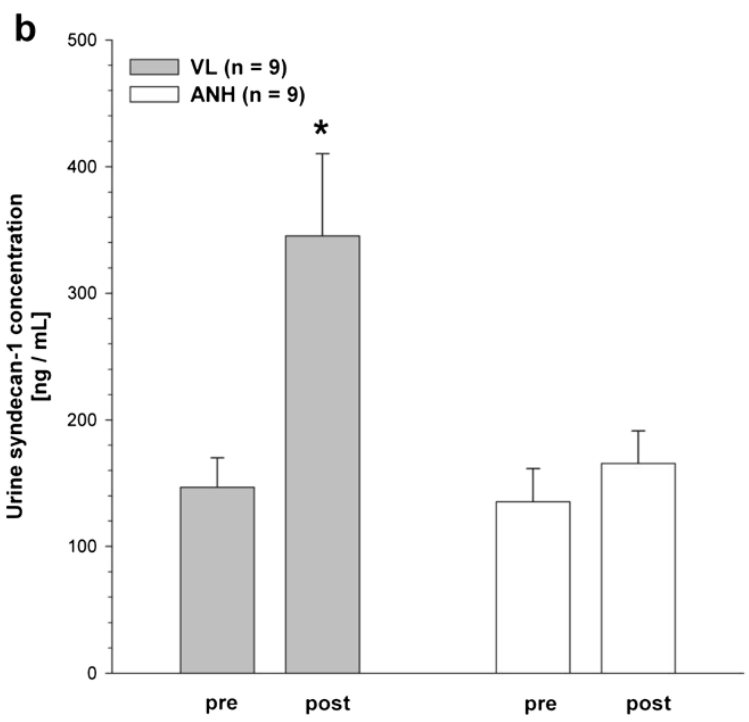

Figure 3 Urinary concentrations of glycocalyx components. Urinary concentrations of heparan sulfate (a) and syndecan 1 (b) before (pre) and after (post) volume loading (VL, $n=9$ ) or acute normovolemic hemodilution ( $\mathrm{ANH}, n=9$ ) with $6 \%$ hydroxyethyl starch 130/0.4. Data are given as mean \pm SEM. ${ }^{*} P<0.05$ (significantly different from pre). 
interstitial space, causing tissue edema. The mechanism behind this colloid shifting seems to be an impaired glycocalyx structure, as evidenced by a considerable decrease in the total volume of the endothelial surface layer [15]. The results of the present study offer an explanation for this phenomenon: ANP is released from human atria during iatrogenic hypervolemia, inducing shedding of constituent parts of the endothelial glycocalyx.

ANP has well-known diuretic, natriuretic and vasodilating effects. Furthermore, this polypeptide hormone also induces rapid shifts of intravascular fluid into the interstitial space $[12,28]$. Experimental and clinical studies have revealed that elevation of ANP is associated with increased shedding of the endothelial glycocalyx $[13,14]$.

A possible connection between the ability of ANP to acutely shift volume from the intra- to extravascular spaces and its influence on the integrity of the endothelial glycocalyx has been investigated in an experimental setting by our group [13]. Infusion of ANP in an isolated heart model caused an increase in fluid leak and an accelerated extravasation of colloid. Furthermore, ANP resulted in rapid shedding of the endothelial glycocalyx and histologically detectable destruction of the coronary vascular glycocalyx [13]. Accordingly, the ANP-induced increase in vascular permeability described in vivo might be related to changes in the integrity of the glycocalyx. This fragile structure is a crucial part of the vascular barrier, and its deterioration has been shown to cause shifting of fluids and colloids into the interstitial space with concomitant tissue edema.

Indirect evidence for such an effect comes from a recent study of patients undergoing coronary artery bypass surgery [14]. Three major components of the endothelial glycocalyx were shed from the endothelium and detected in the circulating blood of patients during both on- and off-pump coronary artery bypass surgeries. Comparison of the respective time courses of glycocalyx shedding with release of ANP and various cytokines designated ANP as the mediator that most likely initiated shedding in both surgical procedures [14].

Perioperative fluid therapy is currently being discussed intensively concerning not only the kind of fluid but also the right amount. A further aspect of debate is when to infuse the fluid. The danger of hypovolemia's causing organ hypoperfusion and increasing the risk of systemic inflammation has been known for decades. However, awareness that hypervolemia can have similar detrimental effects on patient outcomes is relatively new. Fluid overload has been shown to abet anastomotic leakage, pulmonary edema, pneumonia and wound infection, as well as postoperative ileus [10,11,29]. Individually, both the surgical impact (inflammation, trauma) and the traditional liberal fluid strategy have the potential to impair the competence of the vascular barrier. The combination of both confounders increases this effect significantly. A breakdown of vascular barrier competence results in capillary leakage and protein-rich interstitial edema, which lead to a significant perioperative increase in body weight. In clinical trials, this has been shown to be associated with increased morbidity and mortality [9-11]. The data derived from the present study support the need for a rational fluid management strategy to maintain normovolemia by replacing actual losses in an adequate manner and avoid unnecessary fluid boluses.

HES preparations are frequently used in clinical practice because their intravascular volume effect is high and their deposition in tissue is low. Under pathological conditions, however, this might not inevitably be the case. Patients with severe sepsis and in septic shock, for example, need very large amounts of fluid to stabilize cardiac preload. Trials have revealed a significantly decreased volume effect of colloids in this situation, despite remaining superior to crystalloids [30-33]. This effect not only is associated with severe tissue edema but also can cause serious side effects that have a negative impact on patient outcome. Experimental data support the observation that colloids may be retained insufficiently at the vascular barrier during capillary leakage [34]. Our experimental findings are in agreement with these clinical observations linking degradation of the glycocalyx to colloid and fluid extravasation.

One key question is whether the renal or the vascular effects of ANP stand in the foreground. In our study, we measured no difference in urinary output between these groups, although patients in the VL group were subjected to hypervolemia. However, our urine-sampling period terminated directly after fluid infusion and thus was probably too short to detect changes in urinary output. Indeed, Drummer et al. demonstrated that an intravenous volume bolus of $2 \mathrm{~L}$ in healthy volunteers required more than 48 hours to be completely excreted [35]. Nevertheless, the unchanged urine production in our study allowed us to analyze clearly the results obtained for urinary elimination of heparan sulfate and syndecan 1 . The urinary concentration of the former did not differ between pre- and postintervention for either the VL or ANH patients, whereas the syndecan 1 concentration increased in the VL group. Thus, urinary elimination directly reflects the alteration in blood level determined for these two glycocalyx constituents, with no masking or simulation of shedding on the basis of renal clearance.

One limitation of this trial is that biomarkers of glycocalyx shedding are only an indirect method of measuring glycocalyx thickness and integrity and do not provide insight into the thickness of the remaining glycocalyx structure. Furthermore, we used a third-generation balanced 6\% hydroxyethyl starch 130/0.4 solution, so, despite volume effects similar to those seen with other iso-oncotic 
colloids (for example, 5\% human albumin), the results of this trial are not directly transferable to other colloids.

Surprisingly, we found only two markers of glycocalyx degradation to be elevated in the serum of the VL group: syndecan 1 and hyaluronan. It should be borne in mind that shedding of these two constituents requires the action of proteases, whereas the lyase heparanase is needed for shedding of heparan sulfates in humans. Accordingly, VL cannot lead to any marked activation or release of heparanase in humans. A major store of heparanase in humans is in the tissue mast cells [36]. Fittingly, there are no receptors for ANP on the human mast cell. Thus, VL-induced liberation of ANP is a realistic mechanism by which to explain our finding of dissociated markers of glycocalyx damage.

\section{Conclusion}

The results of our trial show that the transfusion-sparing procedure of VL may not be as safe as believed. Hypervolemia has detrimental effects on vascular barrier competence and may impair patient outcome. We recommend abstaining from preoperative volume boluses and favoring ANH should hemodilution be warranted to reduce perioperative red cell transfusion. Future research in general is warranted in the area of fluid administration that takes the glycocalyx into consideration and includes deducing optimal volume amounts and rates of infusion that will maintain intravascular volume without causing disruption of the endothelial glycocalyx.

\section{Key messages}

- ANP is released during preoperative VL.

- VL causes increased shedding of the endothelial glycocalyx.

- Glycocalyx components can be detected in both serum and urine 30 minutes after VL.

- ANH has much lower effects on both glycocalyx shedding and ANP release, respectively.

\section{Abbreviations}

ANH: Acute normovolemic hemodilution; ANP: Atrial natriuretic peptide; BSA: Body surface area; HES: Hydroxyethyl starch; VL: Volume loading.

\section{Competing interests}

DC has delivered lectures funded by, and has received research grants from, B Braun, Grifols and Fresenius Kabi. MJ has delivered lectures funded by, and has received research grants from, Baxter, B Braun, Fresenius Kabi, Grifols and Serumwerk Bernburg, and is a member of the Grifols Albumin Advisory Board. MR has delivered lectures funded by, and has received research grants from, CSL Behring and Fresenius Kabi Serumwerk Bernburg. All of the other authors declare that they have no competing interests.

\section{Authors' contributions}

$D C, D B, P C, B F B$ and MR conceived of and designed the study. DC, DB and $J P$ performed the trial withdrawal and infusion procedures and acquired the data. MJ recruited the patients and performed anesthesia. MV performed ANP measurements. FB and BFB performed measurements of glycocalyx constituents. All authors analyzed and interpreted the data. DC and DB wrote the manuscript. All other authors made critical revisions of the manuscript for intellectual content. All authors read and approved the final version of the manuscript and agree to be accountable for all aspects of the work to ensure that questions related to the accuracy and integrity of any part of the work are appropriately investigated and resolved.

\section{Acknowledgements}

This study was performed using departmental research funding provided by the Bavarian government (Bavarian State Ministry of Science, Research and the Arts, Munich, Germany), which had no influence on the study design; the collection, analysis or interpretation of data; the writing of the manuscript; or the decision to submit the manuscript for publication.

\section{Author details}

${ }^{1}$ Department of Anesthesiology, University Hospital of Munich, Marchioninistrasse 15, 81377 Munich, Germany. ${ }^{2}$ Department of Clinical Chemistry, University Hospital of Munich, Marchioninistrasse 15, 81377 Munich, Germany. ${ }^{3}$ Walter-Brendel Centre of Experimental Medicine, Ludwig-Maximilians-University Munich, Schillerstrasse 44, 80336 Munich, Germany.

Received: 28 April 2014 Accepted: 8 September 2014

Published online: 13 October 2014

\section{References}

1. Pries AR, Kuebler WM: Normal endothelium. Handb Exp Pharmacol 2006, 176:1-40.

2. Curry FE, Adamson RH: Endothelial glycocalyx: permeability barrier and mechanosensor. Ann Biomed Eng 2012, 40:828-839.

3. Pries AR, Secomb TW, Gaehtgens P: The endothelial surface layer. Pflugers Arch 2000, 440:653-666.

4. Weinbaum S, Tarbell JM, Damiano ER: The structure and function of the endothelial glycocalyx layer. Annu Rev Biomed Eng 2007, 9:121-167.

5. Curry FR, Adamson RH: Vascular permeability modulation at the cell, microvessel, or whole organ level: towards closing gaps in our knowledge. Cardiovasc Res 2010, 87:218-229.

6. Burke-Gaffney A, Evans TW: Lest we forget the endothelial glycocalyx in sepsis. Crit Care 2012, 16:121.

7. Nelson A, Berkestedt I, Schmidtchen A, Ljunggren L, Bodelsson M: Increased levels of glycosaminoglycans during septic shock: relation to mortality and the antibacterial actions of plasma. Shock 2008, 30:623-627.

8. Johansson Pl, Stensballe J, Rasmussen LS, Ostrowski SR: A high admission syndecan-1 level, a marker of endothelial glycocalyx degradation, is associated with inflammation, protein C depletion, fibrinolysis, and increased mortality in trauma patients. Ann Surg 2011, 254:194-200.

9. Lobo DN, Bostock KA, Neal KR, Perkins AC, Rowlands BJ, Allison SP: Effect of salt and water balance on recovery of gastrointestinal function after elective colonic resection: a randomised controlled trial. Lancet 2002, 359:1812-1818.

10. Nisanevich V, Felsenstein I, Almogy G, Weissman C, Einav S, Matot I: Effect of intraoperative fluid management on outcome after intraabdominal surgery. Anesthesiology 2005, 103:25-32.

11. Brandstrup B, Tønnesen $H$, Beier-Holgersen $R$, Hjortsø $E$, Ørding $H$, Lindorff-Larsen K, Rasmussen MS, Lanng C, Wallin L, Iversen LH, Gramkow CS, Okholm M, Blemmer T, Svendsen PE, Rottensten HH, Thage B, Riis J, Jeppesen IS, Teilum D, Christensen AM, Graungaard B, Pott F: Effects of intravenous fluid restriction on postoperative complications: comparison of two perioperative fluid regimens: a randomized assessor-blinded multicenter trial. Ann Surg 2003, 238:641-648.

12. Curry FR: Atrial natriuretic peptide: an essential physiological regulator of transvascular fluid, protein transport, and plasma volume. J Clin Invest 2005, 115:1458-1461.

13. Bruegger D, Jacob M, Rehm M, Loetsch M, Welsch U, Conzen P, Becker BF: Atrial natriuretic peptide induces shedding of endothelial glycocalyx in coronary vascular bed of guinea pig hearts. Am J Physiol Heart Circ Physiol 2005, 289:H1993-H1999.

14. Bruegger D, Schwartz L, Chappell D, Jacob M, Rehm M, Vogeser M, Christ F, Reichart B, Becker BF: Release of atrial natriuretic peptide precedes shedding of the endothelial glycocalyx equally in patients undergoing on- and off-pump coronary artery bypass surgery. Basic Res Cardio/ 2011, 106:1111-1121. 
15. Rehm M, Haller M, Orth $V$, Kreimeier U, Jacob M, Dressel H, Mayer S, Brechtelsbauer $\mathrm{H}$, Finsterer $\mathrm{U}$ : Changes in blood volume and hematocrit during acute preoperative volume loading with $5 \%$ albumin or $6 \%$ hetastarch solutions in patients before radical hysterectomy. Anesthesiology 2001, 95:849-856.

16. Rehm M, Orth V, Kreimeier U, Thiel M, Haller M, Brechtelsbauer H, Finsterer U: Changes in intravascular volume during acute normovolemic hemodilution and intraoperative retransfusion in patients with radical hysterectomy. Anesthesiology 2000, 92:657-664.

17. Perner A, Haase N, Guttormsen AB, Tenhunen J, Klemenzson G, Åneman A, Madsen KR, Møller MH, Elkjær JM, Poulsen LM, Bendtsen A, Winding R, Steensen M, Berezowicz P, Søe-Jensen P, Bestle M, Strand K, Wiis J, White JO, Thornberg KJ, Quist L, Nielsen J, Andersen LH, Holst LB, Thormar K, Kjældgaard AL, Fabritius ML, Mondrup F, Pott FC, Møller TP, Winkel P, Wetterslev J, for the 6S Trial Group and Scandinavian Critical Care Trials Group: Hydroxyethyl starch 130/0.42 versus Ringer's acetate in severe sepsis. N Engl J Med 2012, 367:124-134

18. Myburgh JA, Finfer S, Bellomo R, Billot L, Cass A, Gattas D, Glass P, Lipman J, Liu B, McArthur C, McGuinness S, Rajbhandari D, Taylor CB, Webb SAR, for the CHEST Investigators and the Australian and New Zealand Intensive Care Society Clinical Trials Group: Hydroxyethyl starch or saline for fluid resuscitation in intensive care. N Engl J Med 2012, 367:1901-1911.

19. Bruegger D, Rehm M, Abicht J, Paul JO, Stoeckelhuber M, Pfirrmann M, Reichart B, Becker BF, Christ F: Shedding of the endothelial glycocalyx during cardiac surgery: on-pump versus off-pump coronary artery bypass graft surgery. J Thorac Cardiovasc Surg 2009, 138:1445-1447.

20. Zausig YA, Chappell D, Becker BF, Potschka D, Busse H, Nixdorf K, Bitzinger D, Jacob B, Jacob M: The impact of crystalloidal and colloidal infusion preparations on coronary vascular integrity, interstitial oedema and cardiac performance in isolated hearts. Crit Care 2013, 17:R203.

21. Bruegger D, Rehm M, Jacob M, Chappell D, Stoeckelhuber M, Welsch U, Conzen P, Becker BF: Exogenous nitric oxide requires an endothelial glycocalyx to prevent postischemic coronary vascular leak in guinea pig hearts. Crit Care 2008, 12:R73.

22. Rehm M, Bruegger D, Christ F, Conzen P, Thiel M, Jacob M, Chappell D Stoeckelhuber M, Welsch U, Reichart B, Peter K, Becker BF: Shedding of the endothelial glycocalyx in patients undergoing major vascular surgery with global and regional ischemia. Circulation 2007, 116:1896-1906.

23. Chappell D, Jacob M, Hofmann-Kiefer K, Bruegger D, Rehm M, Conzen P, Welsch U, Becker BF: Hydrocortisone preserves the vascular barrier by protecting the endothelial glycocalyx. Anesthesiology 2007, 107:776-784.

24. Fraser JR, Laurent TC, Pertoft H, Baxter E: Plasma clearance, tissue distribution and metabolism of hyaluronic acid injected intravenously in the rabbit. Biochem J 1981, 200:415-424.

25. Lebel L: Clearance of hyaluronan from the circulation. Adv Drug Deliv Rev 1991, 7:221-235

26. Pouta AM, Karinen J, Vuolteenaho OJ, Laatikainen TJ: Effect of intravenous fluid preload on vasoactive peptide secretion during Caesarean section under spinal anaesthesia. Anaesthesia 1996, 51:128-132.

27. Kumar R, Chakraborty I, Sehgal R: A prospective randomized study comparing two techniques of perioperative blood conservation: isovolemic hemodilution and hypervolemic hemodilution. Anesth Analg 2002, 95:1154-1161.

28. Schreier B, Börner S, Völker K, Gambaryan S, Schäfer SC, Kuhlencordt P, Gassner B, Kuhn M: The heart communicates with the endothelium through the guanylyl cyclase-A receptor: acute handling of intravascular volume in response to volume expansion. Endocrinology 2008, 149:4193-4199.

29. Chappell D, Jacob M, Hofmann-Kiefer K, Conzen P, Rehm M: A rational approach to perioperative fluid management. Anesthesiology 2008, 109:723-740.

30. Bayer O, Reinhart K, Kohl M, Kabisch B, Marshall J, Sakr Y, Bauer M, Hartog C, Schwarzkopf D, Riedemann N: Effects of fluid resuscitation with synthetic colloids or crystalloids alone on shock reversal, fluid balance, and patient outcomes in patients with severe sepsis: a prospective sequential analysis. Crit Care Med 2012, 40:2543-2551.

31. Guidet B, Martinet O, Boulain T, Philippart F, Poussel J, Maizel J, Forceville X, Feissel M, Hasselmann M, Heininger A, Van Aken $\mathrm{H}$ : Assessment of hemodynamic efficacy and safety of $6 \%$ hydroxyethylstarch $130 / 0.4$ vs. $0.9 \% \mathrm{NaCl}$ fluid replacement in patients with severe sepsis: the CRYSTMAS study. Crit Care 2012, 16:R94.
32. Annane $D$, Siami $S$, Jaber $S$, Martin $C$, Elatrous $S$, Declère $A D$, Preiser JC, Outin $\mathrm{H}$, Troché $\mathrm{G}$, Charpentier $\mathrm{C}$, Trouillet JL, Kimmoun A, Forceville $\mathrm{X}$, Darmon M, Lesur O, Reignier J, Abroug F, Berger P, Clec'h C, Cousson J, Thibault L, Chevret S, for the CRISTAL Investigators: Effects of fluid resuscitation with colloids vs crystalloids on mortality in critically ill patients presenting with hypovolemic shock: the CRISTAL randomized trial. JAMA 2013, 310:1809-1817.

33. Caironi P, Tognoni G, Masson S, Fumagalli R, Pesenti A, Romero M, Fanizza C, Caspani L, Faenza S, Grasselli G, lapichino G, Antonelli M, Parrini V, Fiore G, Latini R, Gattinoni L, for the ALBIOS Study Investigators: Albumin replacement in patients with severe sepsis or septic shock. $N$ Engl Med 2014, 370:1412-1421.

34. Jacob M, Bruegger D, Rehm M, Welsch U, Conzen P, Becker BF: Contrasting effects of colloid and crystalloid resuscitation fluids on cardiac vascular permeability. Anesthesiology 2006, 104:1223-1231.

35. Drummer C, Heer M, Baisch F, Blomqvist CG, Lang RE, Maass H, Gerzer R: Diuresis and natriuresis following isotonic saline infusion in healthy young volunteers before, during, and after HDT. Acta Physiol Scand 1992, 604:101-111.

36. Becker BF, Chappell D, Jacob M: Endothelial glycocalyx and coronary vascular permeability: the fringe benefit. Basic Res Cardiol 2010, 105:687-701.

doi:10.1186/s13054-014-0538-5

Cite this article as: Chappell et al:: Hypervolemia increases release of atrial natriuretic peptide and shedding of the endothelial glycocalyx. Critical Care 2014 18:538.

\section{Submit your next manuscript to BioMed Central and take full advantage of:}

- Convenient online submission

- Thorough peer review

- No space constraints or color figure charges

- Immediate publication on acceptance

- Inclusion in PubMed, CAS, Scopus and Google Scholar

- Research which is freely available for redistribution 